\title{
Children Have the Capacity to Think Multiplicatively, as long as ...
}

\author{
Chris Hurst ${ }^{1 *}$ \\ 1 School of Education, Curtin University, AUSTRALIA \\ *Corresponding Author: c.hurst@curtin.edu.au \\ Citation: Hurst, C. (2017). Children Have the Capacity to Think Multiplicatively, as long as .... European \\ Journal of STEM Education, 2(3), 07. https://doi.org/10.20897/ejsteme/78169
}

Published: December 28, 2017

\begin{abstract}
Multiplicative thinking has been widely accepted as a critically important 'big idea' of mathematics and one which underpins much mathematical understanding beyond the primary years of schooling. It is therefore of importance to consider the capacity of children to think multiplicatively but also to consider the capacity of their teachers to teach multiplicative thinking in a conceptual manner. This article focusses specifically on the conceptual links between the multiplicative array, the notion of numbers of equal groups in the multiplicative situation, factors and multiples, the commutative property of multiplication, and the inverse relationship between multiplication and division. A study involving a large sample of primary school students found that whilst most students demonstrated an understanding of some of the aforementioned elements, hardly any of the students were able to connect the ideas or to explain them in terms of each other. As a consequence of the findings, the impact of teacher knowledge on children's capacity to think multiplicatively was considered.
\end{abstract}

Keywords: multiplicative thinking, connected knowledge, teacher knowledge, arrays, factors, commutativity, inverse relationship, multiplication, division

\section{INTRODUCTION}

Multiplicative thinking is acknowledged as a 'big idea' of mathematics (Hurst and Hurrell, 2014; Siemon, Bleckley and Neal, 2012) which underpins much of the mathematics learned beyond the middle years of primary/elementary schooling. Aspects of multiplicative thinking, multiplication, and division have been variously described by mathematics researchers and educators. However, few people have offered a definition that adequately covers the broad scope of multiplicative thinking. The following definition, based on the work of Siemon, Breed, Dole, Izard and Virgona (2006) and Siemon, Bleckley and Neal (2012) is offered here. Multiplicative thinking is demonstrated by an ability to

- Work flexibly with a wide range of numbers including very large and small whole numbers, decimals, fractions, ratio and percentage;

- Work conceptually with the relative magnitude of whole and decimal numbers in a range of representations, demonstrating an understanding of the notions of 'times bigger' and 'times as many';

- Demonstrate a conceptual understanding of the multiplicative situation, the relationship between multiplication and division, numbers of equal groups, factors and multiples, and the various properties of multiplication; and

- Articulate a conceptual understanding of a range of multiplicative ideas in a connected way with explicit language and terminology. 
It is evident from the definition that multiplicative concepts are complex but connected and this will be explored shortly. However, while this article explores the extent to which primary/elementary students have the capacity to think multiplicatively, there is a key factor at play - the mathematical content knowledge of teachers - and whether that content knowledge is held in a connected and conceptual way. Thanheiser, Philipp, Fasteen, Strand and Mills (2013, p. 137) note that '. . . teachers' mathematical content knowledge continues to be a major area of concern' despite the best efforts of universities and professional learning providers to offer courses specifically designed to develop teacher knowledge. Thanheiser et al. (2013, p. 137) also noted that

"the fact that most PSTs [Pre-Service Teachers] and teachers do not understand the rationales behind the procedures they teach is a major concern for those of us responsible for teaching PSTs".

Whilst Thanheiser et al. reported on a study of PST knowledge, it seems reasonable to suggest that the same situation might apply to teachers already serving in classrooms. This raises an important question. If teachers hold their content knowledge in an unconnected and procedural way, might that inhibit students' ability to make multiplicative connections and thus develop a conceptual rather than procedural view of multiplicative ideas? This article essentially focuses on the capacity of students to think multiplicatively but it necessarily follows that teacher knowledge will be part of that discussion.

\section{BACKGROUND}

As previously mentioned, this article explores several ideas within the multiplicative situation - the multiplicative array, factors and multiples, commutativity, numbers of equal groups, and the inverse relationship between multiplication and division. Hence, it is essentially about understanding the structure of the mathematics, and to find out if primary school students can see the connections between those ideas. This then demands consideration of teacher knowledge. In the following overview, although the five main listed ideas are considered individually, inevitably, there is a degree of crossover as the ideas are inexorably connected with one another.

\section{Arrays and Equal Groups}

In his article reporting on a group of middle school teachers engaging in 'concept study', Davis (2008) points to the importance of conceptual understanding and implies that teachers need to have a deep knowledge of key concepts such as multiplication. As part of the 'concept study' and prior to their group meetings, teachers involved their students in discussions around ideas such as 'What are factors and products?' and 'What is division?' They also considered ideas like 'What are some of the different ways you can talk about multiplication? How might you draw it?' (Davis, 2008, p. 91). The last two questions allude to a strong case for the use of the array (the merits of which will be discussed in more detail) as a model for understanding the multiplicative situation. The sort of classroom activity described by Davis goes to the heart of what could be considered to be the key issue here teachers needing to hold a deep and connected understanding of multiplicative concepts and be able to make the connections explicit to their students (Charles, 2005; Clarke, Clarke and Sullivan, 2012; Hurst, 2015). Knowing about factors and products, and the array as a representation of the multiplicative situation, are significant parts of that.

The central importance of the array has been described by others including Jacob and Mulligan (2014), YoungLoveridge (2005), and Young-Loveridge and Mills (2009). Askew's (2016) discussion of the array underlines an important aspect of the connections that need to be realised, identified and understood by children. He says that teachers need to assist children to move 'from using them as models of to being models for and then to becoming tools for thinking with' (Askew, 2016, p. 139). In other words, teachers need to make the connections between the array and ideas such as factors, equal groups, the inverse relationship between multiplication and division, and the development of the algorithm from the grid method. Askew (2016) supports this, noting that the array supports the understanding of connections between multiplication and division.

It is Askew's (2016) point that the array needs to be much more than a symbolic representation and more of 'a tool for thinking with' that is of interest. It is essential that the array is not something that is briefly introduced and 'covered' superficially. Rather the array needs to part of the language of the mathematics classroom at all times and used as a key tool for helping children understand the structure of the multiplicative situation. For this to occur, teachers need to understand how and why the array is important.

Matney and Daugherty (2013) are very clear about the power of the array to help students visualize mathematical structures like commutativity and distributivity, adding that students' computational errors may be compounded by their lack of understanding of what they are doing. They note that students are better able to understand commutativity when they rotate the array through ninety degrees. However, more important is that they encourage students to "consider why it might be advantageous to think of $4 \times 7$ and $7 \times 4$ as different, even though the 
product is the same through commutativity" (Matney and Daugherty, 2013, p. 151-152). In terms of mathematical structure, it is important to understand that the product in both cases is the same. However, being able to understand and articulate that four groups of seven is quite a different multiplicative situation to seven groups of four, demonstrates more powerful knowledge.

\section{Factors, Factorisation, and Divisibility}

Feldman (2014) discusses activities involving prime factorisation of numbers as an important part of number theory. He notes that an understanding of factors helps students to “. . . identify the relationship between a factor and its multiples and make sense of important properties such as the distributive, associative, and commutative properties" (Feldman, 2014, pp. 231-232). Rather than students simply being able to identify factors, one consequence of a deep understanding of factors is that students are able to work more flexibly and efficiently with a range of numbers (Feldman, 2014) which supports the definition of multiplicative thinking provided earlier. Feldman also notes that, despite the general paucity of research into middle school students' mathematical understanding, there is sufficient evidence to show that a strong understanding of factors leads to a better understanding of key algebraic concepts.

This is supported by some earlier work from Zazkis and Campbell (1996). In discussing "the encapsulation of divisibility", they note that many of the participants in their study (in this case pre-service teachers) had not connected divisibility with multiplication, factors, or distributivity, saying that there is a need for an explicit pedagogical approach to the inverse relationship (p. 562). Further, they make a powerful point that

If one is to meaningfully continue in mathematics, the basic concepts of arithmetic must be grasped. If this is not happening in the middle grades, then it should come as no surprise that many students fail to make a successful transition to algebra. We believe that developing a conceptual understanding of divisibility and factorization is essential in the development of conceptual understanding of the multiplicative structure of numbers (Zazkis and Campbell, 1996, p. 562).

They imply that, rather than teach multiplication and division and multiplication separately, there is a need to consider the 'multiplicative situation' as a whole and make explicit connections between ideas like factorisation, properties of multiplication, and the inverse relationship.

Young-Loveridge and Mills (2009) studied the use of 'dotty arrays' with a group of Year 7 and 8 students (aged 12 and 13 years), and found that the array was helpful in supporting students' understanding of the algorithm for multiplying two 2-digit numbers. They specifically use the term 'factor' in describing how the array was useful noting that students needed to be able to partition the two digit factors and also that dotty arrays helped students to visualise the rectangular grid representation of multiplication (Young-Loveridge and Mills, 2009). YoungLoveridge and Mills also cite the New Zealand Numeracy Development Project (Ministry of Education, 2007) materials that multiplicative thinking involves, amongst other things, the construction and manipulation of factors. This seems to imply that the language of factors ought to be explicitly used with students to consolidate the connection with arrays.

\section{Commutativity}

Anthony and Walshaw (2000) found that students aged 9 and 13 years struggled to articulate an understanding of commutativity and did not display any real depth of multiplicative thinking. In particular, they noted that students were unable to recognize the connection between the array and the commutative property of multiplication and despite being able to engage in discussion, were very imprecise in terms of explaining commutativity. Students used terms like 'switch arounds' and 'turnarounds' and a range of similar terms but could not actually explain why the commutative property worked in terms of a model such as the array, or the language of factors and multiples. They stated it in these terms:

"None of the sampled students appeared to construct and coordinate composite units through an array - visualizing the array in two unique orientations - that would be suggestive of reasoning multiplicatively and thinking in commutative terms" (Anthony and Walshaw, 2000, p. 97).

Warren and English (2000) arrived at a similar conclusion following a study of a group of 10-12 year old students. Whilst almost all of the students $(95.7 \%)$ could identify the commutative property, only $60.6 \%$ of them could generate another example of it, and only $13.8 \%$ could generate two further examples. As well, they found that only $17 \%$ of students could offer a valid explanation but this was generally in terms of 'switching the numbers around' and not in terms of the array or factors and multiples. In noting that this is indicative of students not understanding the structure of the mathematics, they stated that this lack of understanding is largely due to the use of computational procedures rather than the exploration of mathematical relationships (Warren and English, 2000). 
Squire, Davies and Bryant (2004) also noted the importance of students developing a conceptual understanding of the mathematics that underpins multiplication facts and algorithms. They note a number of benefits from students developing a strong conceptual understanding including greater flexibility in their thinking, working quicker, deriving unknown facts from known facts, and being more efficient at solving problems (Squire et al., 2004). They discuss the results of a study showing students being more efficient at identifying and using the commutative property than the distributive property but at no stage were children asked to consider why the property works. Indeed, in noting the underlying importance of commutativity, they added that it is vital for educators to consider how to develop children's understanding of commutativity (Squire et al., 2004). This must go beyond describing in terms of a 'switch around' as discussed by Anthony and Walshaw (2000). Baroody (1999, p. 184) also indicated the importance of the commutative property in terms of students being able learn multiplication facts noting that if students 'did not understand the commutative relationship ... they would have lacked the means to generalize their learning'. The key word here is 'understand', again at a more significant level than simply identifying the commutative property or describing in terms of 'turn arounds'. Holding knowledge that the order can be changed is at a lower level than understanding why the same product is obtained.

Larsen's (2010) work with a small group of undergraduate students appears to support this. He states that a likely reason for students experiencing difficulties with the associative and commutative properties may be that too much imprecise and informal language is used in classrooms to describe these properties (Larsen, 2010). Again, there is a strong indication that teachers need to understand the structure of the mathematics around the commutative property and explicitly use terminology such as 'factors and multiples' and the array as a model for understanding the property, rather than allow students to continue to discuss commutativity in terms of 'switch arounds' and the like.

\section{Numbers of Equal Groups and the Inverse Relationship}

In their discussion of the importance of the array, Jacob and Mulligan (2014) focus on the structure of the multiplicative situation based on numbers of equal groups, beginning in the early years of schooling. They write that the structural relationship between multiplication and division needs to be emphasised before formal recording with symbols is introduced. As well, students need to be able to think simultaneously about all three quantities the total, the number of groups and the number in each group - and more importantly, use the associated mathematical language of factors and multiples. However, they note that, unless teaching is explicit, '. . the relationship between multiplication and division may go unnoticed by many students. The array can be used to focus students' attention on that relationship' (Jacob and Mulligan, 2014, p. 37). Jacob and Mulligan also point out that an understanding of commutativity can be greatly enhanced by the use of the array.

Siemon (2013) goes further and points out that the traditional approach is to teach multiplication before division whereas children are accustomed to the notion of sharing or splitting into equal groups, which is where the early emphasis should lie. Her example of the use of the nursery rhyme, 'Baa Baa Black Sheep', when a teacher asked a class of five year olds what would happen if there were five sheep, is quite powerful. Siemon (2013, p. 45) indicates that

"This is essentially a ratio or times as many idea [e.g., 3 times as many bags of wool as sheep] and is quite distinct from the equal group idea".

The 'times as many' notion needs to be explicitly linked to the language of the multiplicative situation to develop a rich understanding of the inverse relationship. Siemon (2013) also underlines the importance of the array model as a basis for understanding multiplication with larger numbers and implies that the language of factors and multiples needs to be explicitly used to ensure that students' understanding of the multiplicative situation is allowed to fully develop. The language of factors and multiples, 'times bigger', and 'scaling up and down' are important tools for mathematizing - reasoning in a mathematical manner through having the language tools to consider or articulate ideas mathematically.

Downton (2013) used a sample of eight year old students and explored their methods of solving a range of division problems, rather than focus on whether the problem was based on partitive or quotitive division. She found that students intuitively used multiplication strategies to solve the division problems, irrespective of whether the problems were partitive or quotitive in nature. Downton suggests that it is the relationship between multiplication and division and the use of a rich variety of problem types in the early years that is a key factor in helping students to think multiplicatively. In an earlier article, Downton (2008) also said that students needed to experience a range of semantic structure and contexts in solving multiplicative problems, noting again the importance of the relationship between multiplication and division and the associated language before any use of symbols or formal recording is introduced. 


\section{Connected Knowledge}

In an editorial column, Gojak (2013) considered the role of elementary teachers, noting that the aim of classroom instruction needs to be to develop deep conceptual understanding. She concluded that if students are to develop such solid conceptual understanding of mathematics, then it follows that their teachers must deeply understand those mathematical concepts (Gojak, 2013). The implication is that this 'deep understanding' includes a knowledge of how the 'big ideas' such as multiplicative thinking are made up of many other ideas, the connections within and between which must be deeply understood by teachers. This is supported by the work of others such as Chick, Pham, and Baker (2006) in developing a framework for analysing pedagogical content knowledge, albeit in the context of a study about the subtraction algorithm. In particular, they referred to teachers' ability to identify the critical components of a concept so that they are able to help their students understand and apply that concept (Chick et al., 2006). It could be said that the connections between the five ideas described earlier (the multiplicative array, factors and multiples, commutativity, numbers of equal groups, and the inverse relationship between multiplication and division) is an example of such connected knowledge needed by teachers.

Since Skemp's (1976) seminal article on the merits of teaching for relational understanding as opposed to instrumental understanding, others have made similar strong statements about the need for teachers to hold a broad and deep connected knowledge of mathematical concepts. Ma (2010) described this in terms of 'Profound Understanding of Fundamental Mathematics' (PUFM) and 'knowledge packages', which could be described as representations of connections between ideas. Despite there being widespread acknowledgement of the worth of such work, there is also plenty of evidence to suggest that many teachers do not hold knowledge for teaching mathematics in those ways. For example, following a study of four primary teachers and their classes, Mills (2015, p. 435) concluded that

"[the] teachers seldom exhibited a deep and thorough conceptual understanding of aspects of the mathematics they were teaching ... [which] contributed to their confusion within the key mathematical concepts they were teaching, and the significance of consistently using correct mathematical language".

Mills (2015) also stated that teachers did not make connections between ideas, nor did they display strong number sense.

Sullivan (2008) underlines the vital importance of teachers holding their mathematical knowledge in a connected way. He implies the necessity for teaching to be explicit and to highlight the ways in which ideas are connected as 'the connection between the representations and the concepts may be difficult for students to ascertain for themselves' (Sullivan, 2008, p. 7). This supports the findings of an earlier study by Askew, Brown, Rhodes, Wiliam and Johnson (1997) which determined that the most effective teachers of numeracy were those who held a 'connectionist' view of mathematical knowledge.

\section{METHODOLOGY}

The study reported on here is part of an on-going project into children's multiplicative thinking. The research questions under consideration are:

- To what extent do children in Years 4, 5 and 6 (i.e., of ages 9, 10, and 11 years) think in a connected way to explain multiplicative concepts?

- What is the extent of teacher knowledge of multiplicative concepts?

Multiplicative thinking was defined earlier and this article is concerned with two parts of that definition:

- Demonstrate a conceptual understanding of the multiplicative situation, the relationship between multiplication and division, numbers of equal groups, factors and multiples, and the various properties of multiplication

- Articulate a conceptual understanding of a range of multiplicative ideas in a connected way with explicit language and terminology.

Data have been generated from two sources - a written Multiplicative Thinking Quiz (MTQ), and some teacher interviews. These instruments have been developed over the three and half year life of the project. The student sample $(\mathrm{n}=545)$ for this article is drawn from 17 Western Australian classes and two classes in the south-west of England and consists of 167 Year 4 students (aged 9 years), 205 Year 5 students (aged 10 years), and 173 Year 6 students (aged 11 years). Responses from the MTQ were manually entered onto an Excel spreadsheet and correct responses were denoted by a ' 1 ' with incorrect responses given a ' 0 '. Tallies were then generated using the 'sum' tool. 


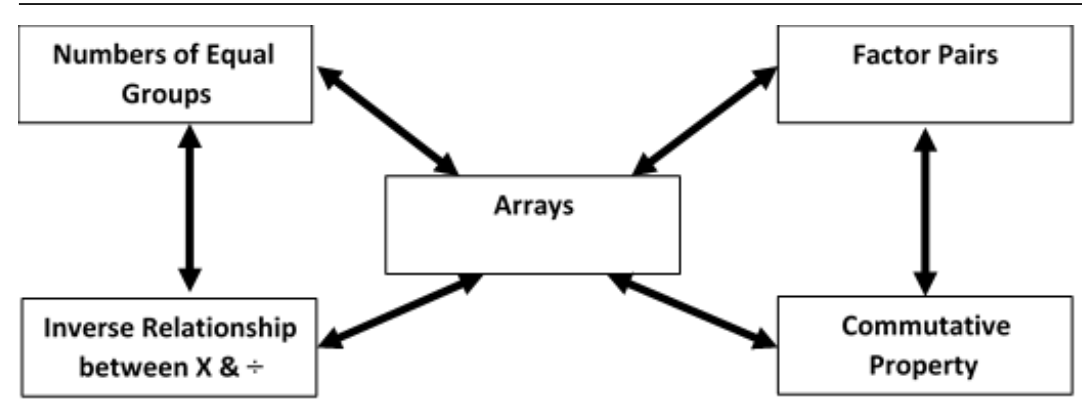

Figure 1. Conceptual Framework

Table 1. MTQ questions related to the conceptual framework

\begin{tabular}{|c|c|c|}
\hline Target Idea & Wording of Question & Responses Sought \\
\hline $\begin{array}{l}\text { Numbers of equal } \\
\text { groups }\end{array}$ & $\begin{array}{l}\text { 1(b) What do the numbers in } 8 \times 7 \text { tell you? } \\
1 \text { (c) Write a story (a word problem or a story } \\
\text { problem) that shows what } 8 \times 7 \text { means. }\end{array}$ & $\begin{array}{l}\text { States that } 8 \text { means the number of groups and } 7 \\
\text { means the number in each group. } \\
\text { Writes a story problem that reflects numbers of } \\
\text { equal groups. }\end{array}$ \\
\hline Arrays & $\begin{array}{l}\text { 2(a) Draw a picture (using dots or crosses) that } \\
\text { shows the expression } 4 \times 3\end{array}$ & $\begin{array}{l}\text { A 'tight' array is drawn with only small gaps between } \\
\text { items. }\end{array}$ \\
\hline Arrays & 2(b) Can you draw it in another way? & Drew a rotated array \\
\hline Factors & $\begin{array}{l}3 \text { (iii) Write as many different multiplication } \\
\text { sentences as you can that will give you an answer of } \\
24\end{array}$ & $\begin{array}{l}\text { Writing all factors for } 24 \\
\text { Writing factors as commutated factor pairs }\end{array}$ \\
\hline Factors & 4(a) (iii) Write as many factors of 30 as you can. & $\begin{array}{l}\text { Writing all factors for } 30 \\
\text { Writing factors as commutated factor pairs }\end{array}$ \\
\hline Commutative Property & $\begin{array}{l}7 \text { (a) Which of the following will give you the same } \\
\text { answer as } 6 \times 17 \text { ? }(16 \times 7)(17 \times 6)(7 \times 16) \\
7 \text { (b) Give a reason for two of your choices of 'Yes' } \\
\text { or 'No' answers }\end{array}$ & $\begin{array}{l}\text { Identifies the expression which demonstrates the } \\
\text { commutative property. } \\
\text { Provides an explanation based on equal groups, or } \\
\text { factors, or the rotated array. }\end{array}$ \\
\hline $\begin{array}{l}\text { Inverse relationship } \\
\text { between multiplication } \\
\text { and division }\end{array}$ & $\begin{array}{l}8 \text { (a) If you know that } 24 \times 6=144 \text {, which of the } \\
\text { following must you be able to work out from that? } \\
(144 \div 6)(144 \times 6)(144 \div 24)(144 \times 24) \\
8(b) \text { Give a reason for two of your choices of 'Yes' } \\
\text { or 'No' answers. }\end{array}$ & $\begin{array}{l}\text { Identifies expressions which reflect the inverse } \\
\text { relationship. } \\
\text { Provides an explanation based on factors, multiples, } \\
\text { or products, or the array. }\end{array}$ \\
\hline
\end{tabular}

The conceptual framework for this study is based on part of a draft model for multiplicative thinking which is underpinned by the earlier background discussion. The framework draws on the connections between the five aspects of multiplicative thinking already discussed and is shown as Figure 1.

The conceptual framework is based on several propositions - that the commutative property can be understood and explained using arrays and factor pairs; the inverse relationship can be understood and explained using arrays and the concept of equal groups (as well as factors); and that the associated mathematical language needs to embedded in classroom discourse to enable students to articulate their thinking. Questions around the five ideas were developed and included in the MTQ. The questions were designed to identify whether or not students knew about aspects of multiplicative thinking, but more importantly, if they could articulate a clear and connected understanding of them based on mathematical structure. Table 1 shows the specific questions as they relate to each of the five aspects of Figure 1 along with the particular responses sought by the research team. The wording of each question was kept reasonably open to see what students' informal responses would be. For instance, the wording of Questions 3(iii) and 4(a) (iii) did not make mention of 'pairs' because it was important to see if students informally wrote the factors in pairs and indeed if they wrote them in 'commutated pairs' (i.e., $8 \times 3$ and $3 \times 8$ ). When the MTQ was administered, each question was read out and students were given a reasonable amount of time to write an answer before the next question was read. This was done to minimise any potential difficulties which any students may have had with regard to the language used in the questions.

\section{RESULTS AND DISCUSSION}

\section{Overview}

The results from the complete sample $(n=545)$ varied considerably from question to question. The great majority of students were able to identify the correct expressions in Questions 7a and 8a which demonstrated the commutative property (93.8\%) and inverse relationship (86.6\%) respectively. However, a very small number of students could adequately explain why the commutative property $(1.8 \%)$ or the inverse relationship $(1.8 \%)$ work. The results from the full sample are shown in Table 2. 
Table 2. Correct responses to the selected questions shown as percentages

\begin{tabular}{lcc}
\hline Question and target aspect & $\mathbf{n = 5 4 5}$ & $\mathbf{\%}$ \\
\hline 1c Numbers of equal groups for 8 x 7 or story to reflect that & 249 & 45.7 \\
\hline 2b(iii) Draws array to represent 4 x 3 & 307 & 56.3 \\
\hline 3(iii) Writes commutated factor pairs for 24 and/or 30 & 206 & 37.8 \\
\hline 4a(iii) Identifies all factors of 24 and/or 30 & 179 & 32.8 \\
\hline 7a Identifies expressions showing the commutative property & 511 & 93.8 \\
\hline 7b Explains commutative property appropriately & 10 & 1.8 \\
\hline 8a Identifies expressions showing inverse relationship & 472 & 86.6 \\
\hline 8b Explains inverse relationship appropriately & 12 & 2.2 \\
\hline
\end{tabular}

Table 3. Percentages of students by age/year groups recording correct responses to the eight questions

\begin{tabular}{lccc}
\hline Questions & $\begin{array}{c}\text { Year 4 } \\
\mathbf{9} \text { yrs }\end{array}$ & $\begin{array}{c}\text { Year 5 } \\
\mathbf{1 0} \text { yrs }\end{array}$ & $\begin{array}{c}\text { Year 6 } \\
\mathbf{1 1} \text { yrs }\end{array}$ \\
\hline 1c Numbers of equal groups for 8 x 7 or story to reflect & 35.3 & 49.0 & 52.0 \\
\hline 2b(iii) Draws array to represent 4 x 3 & 62.9 & 60.8 & 44.5 \\
\hline 3(iii) Writes commutated factor pairs for 24 and/or 30 & 24.0 & 46.6 & 42.2 \\
\hline 4a(iii) Identifies all factors of 24 and/or 30 & 15.0 & 33.3 & 49.7 \\
\hline 7a Identifies expressions showing commutative property & 94.0 & 92.6 & 94.8 \\
\hline 7b Explains commutative property appropriately & 0.6 & 1.5 & 3.5 \\
\hline 8a Identifies expressions showing inverse relationship & 80.8 & 86.8 & 87.2 \\
\hline 8b Explains inverse relationship appropriately & 0.6 & 2.0 & 4.0 \\
\hline
\end{tabular}

Table 4. Numbers of students recording various correct responses to the six questions

\begin{tabular}{lcc}
\hline Number of correct responses for six questions & Number of students $(\mathbf{n}=\mathbf{5 4 5})$ & $\mathbf{\%}$ \\
\hline 8 correct responses & 3 & 0.6 \\
\hline 7 correct responses & 4 & 0.7 \\
\hline 6 correct responses & 57 & 10.5 \\
\hline 5 correct responses & 95 & 17.4 \\
\hline 4 correct responses & 113 & 20.7 \\
\hline 3 correct responses & 127 & 23.3 \\
\hline 2 correct responses & 102 & 18.7 \\
\hline 1 correct responses & 34 & 6.2 \\
\hline 0 correct responses & 10 & 1.8 \\
\hline
\end{tabular}

Just as there were obvious differences in the percentages of correct responses across the different questions, there were also clear differences in the students' responses to particular questions. That is, of the students who identified that the 8 and 7 in the given number fact showed the number of groups and number in each group, not all of them also wrote a word story that reflected that, and vice versa. Similarly, not all students who wrote all factors and showed commutated pairs for 24 , also did so for 30 . Over the whole sample, there were only 10 students $(1.8 \%)$ who did not provide a single correct response to any question. Conversely, there were only seven students, about $1.3 \%$, who correctly responded to seven or eight questions. Hence, it is obvious that the vast majority of students $(98.7 \%$ ) responded correctly to varying numbers of questions. It is also of interest to consider the breakdown of the correct responses in terms of year/age groups. This is shown in Table 3.

There is some difference in the level of correct responses for students of different ages. There is almost three times as many students in the 11 year (Year Six) group being able to identify all factors of 24 or 30 compared to the 9 years (Year Four) group. Similarly, there are more of the older students writing factors as commutated pairs and identifying the numbers of equal groups in a number fact.

It is not clear why this is so and seeking an explanation is not within the scope of this article. However, the observation that less students in the 11 years group (Year Six) depicted the number fact with an array is of interest and will be discussed in the context of teacher comments in a later section.

The main focus here was whether or not students were displaying a conceptual understanding of the properties and relationships and were able to connect the ideas shown in the definition provided earlier. For example, rather than simply being able to identify properties and relationships, it was of interest to see if students could explain why they worked. The number of students providing various numbers of correct responses (from 0 to 8 ) is shown in Table 4.

Some observations can be made from the data generated from the eight questions. First, analysis of the responses to Questions 1c (equal groups), 2b (iii) (arrays), 3(iii) (writing factors in pairs), and 4(iii) (identifying factors), which deal with the conceptual tools for explaining why the inverse relationship and commutative property work, indicates that $10.3 \%$ of the students $(n=56)$ correctly responded to all four questions. However, only three were able to adequately explain both the relationships. Second, within the $69.0 \%$ of students who provided one, two, three, or four correct responses, there was no particular pattern or combination of correct 
answers. That is, some students identified numbers of equal groups, drew an array, and identified factors but did not write factors as commutated pairs, while other students wrote factors in commutated pairs for one number, and drew an array but did not identify numbers of equal groups or factors of the other given number. In summary, apart from the three students who did provide correct responses for all questions, students did not connect their knowledge of the first four questions to the commutative property or inverse relationship.

\section{Questions 1(b) and 1(c) Numbers of Equal Groups}

Altogether, 249 students $(45.6 \%)$ were able to articulate that the numbers in a basic multiplication fact ( $8 \times 7)$ represented the number of groups and the number in each group, and/or wrote an appropriate word problem which reflected that. Only 37 students were able to discuss in terms of numbers of equal groups in Question 1(b) but 155 students were able to write a word problem or story problem that reflected an understanding of equal groups as in Question 1(c). Also, 94 students wrote correct responses for both questions. An interesting observation is that eight students, all from the same class, described the number fact $(8 \times 7)$ in terms of factors. For example, Student RDA (Class HP5) said "The 8 and 7 are factors so you times them to make a product". No students from any other classes described those numbers - in Question 1(b) - as 'factors'. However, of the eight students who did so, only one was also able to provide all the factors of 24 or 30 , and show factors as commutated pairs. This suggests that there may have been some explicit teaching about factors to that class but the students had not connected their understanding to different situations or contexts. The word problems or story problems written were typified by Student DRA (Class HP5) who said "There are seven sweets in each jar and there are eight jars. How many sweets altogether?" Student BHA (Class HP5) wrote a similar story: "There are eight boxes and there were seven apples in each box. How many apples were there altogether?”

\section{Questions 2(a) and 2(b) Arrays}

A total of 307 students (53.4\%) represented the number fact $4 \times 3$ as an array, and of them 83 responded to Question 2(b) by showing a rotated or commutated array. Despite holding knowledge that the array could be rotated, only ten of the 83 students were able to explain how the commutative property works, two of whom drew two commutated arrays to demonstrate it. Further to this, only two students explained the commutative property by drawing two commutated arrays - Student ALE (Class PA5) and Student SHE (Class RA6).

\section{Question 3(iii) Commutated Factor Pairs}

Altogether, 269 students (46.8\%) wrote at least one pair of factors, as for example, (8, 3), (8 x 3), or (8 and 3). This may suggest the existence of a level of understanding about the multiplicative situation in that if one factor and a product (in this case 24) is known, then the other factor is known. As well, 206 of those students went on to show at least three sets of commutated pairs of factors for either 24 or 30 . These were generally represented as $6 \times 5$ and $5 \times 6,10 \times 3$ and $3 \times 10$, though some students such as DAT (Class HP6) wrote them vertically as $1 \times 24$ $=24,2 \times 12=24,3 \times 8=24$, and so on to $12 \times 2=24$ and $24 \times 1=24$. Notwithstanding, only ten students were able to connect their knowledge of factor pairs and use it to explain the commutative property or the inverse relationship. Some examples of strong explanations of those properties follows shortly.

\section{Question 4 Writing Factors of 30 (or 24)}

The majority of students (456 or $79.3 \%$ ) wrote at least one factor for 24 and/or 30 . This seems to indicate a knowledge of what a factor is, even though the students may have been unable to articulate that. A total of 179 students $(31.4 \%)$ were able to show all of the factors of 24 and/or 30. These were recorded in a variety of ways with no representation being more common than any other. Some students listed the factors in pairs (e.g., $1 \times 24$, $2 \times 12,3 \times 8$ and $4 \times 6$ ) and others listed them in order (e.g., 1, 2, 3, 4, 6, 8, 12, and 24). Again, although a large number of students were able to show at least some factors and almost a third of the cohort could list all the factors of a number, only a small number could connect that knowledge to an articulation of how the inverse relationship worked.

\section{Question 7(b) Commutative Property.}

The title of this article mentions the 'capacity' of children to think multiplicatively. The responses of some students to Question 7(b) suggest that such a capacity exists. Ten students were able to explain how the commutative property works and it has been noted already that Student ALE (Class PA5) and Student SHE (Class RA6 drew two commutated arrays (a $6 \times 17$ array and a $17 \times 6$ array) to explain commutativity. Two other students made mention of factors in their responses. Student ZIX (Class PA5) said: 'You'll get the same answer as when you switch the factors around. It is also the same with addition' and Student NAY (Class PA5) said 'If the factors are the same, even if they are switched around, the product will always be the same'. It is of interest that both students are from the same class, as were the eight students from another class who used the term 'factor' to describe the situation with the number fact in Question 1(b). Student BRO (Class PH6) said something similar but 
did not use the term 'factor': ' $17 \mathrm{x} 6$ will give the same answer [as $6 \times 17$ ] because it's the same numbers and in multiplication, it doesn't matter which order you do it in'. Five other students justified that $17 \times 6$ would give the same answer as $6 \times 17$ by saying 'Because 6 groups of 17 will give the same answer as 17 groups of 6' (or similar wording).

A further 13 students in two classes - PH5 and PH6 - simply responded with 'Because it's the commutated law [or commutative law]'. These responses have been discounted as explanations because they don't actually say how or why the property works. It is worth noting that, out of the 545 students from 19 classes, these 13 students (from two classes at the same school) were the only students to use the words 'commutative' or 'commutated'. This strongly suggests that, although there seems to have been some explicit teaching about the commutative property in those two classes, students have not connected their knowledge of factors to explaining why the property works.

\section{Question 8(b) Inverse Relationship}

As with the previous question, it is suggested that responses from some students to Question 8(b) also indicate that the 'capacity' to think multiplicatively exists. Five of the ten students who could articulate why the inverse relationship worked did so in terms of factors. Student RCO (Class PH5) said ' $144 \div 6$ will help you because you can find the other factor. It is also the same for $144 \div 24$ ' and JOS (Class SA6B) said 'Because 24 is the factor you used to get 144 so that's the answer if you divide it by 6 , the other factor'. Student JES (Class PA6) explained it this way: 'Yes, in the first sum, $(24 \times 6=144)$, it gives you the factors so when you divide, you know that 6 lots of 24 go into 144 (do a swap around) and you have the answer'. Student RDA (Class PH5) gave a similar answer while Student NAY (Class PA5) said that 'Because from the two problems, the product divided by the factor will give the missing factor'.

Five other students explained the relationship in terms of equal groups. Student ZIX (Class PA6) said 'It is correct because if 24 groups of 6 marbles equals 144 and you grab all the 144 marbles and divide them into 6 equal groups, you'll get 24 marbles in each group'. Student BEN (Class PA4), RAE (Class PA6) and Student ALE (Class RA6) also described their thinking in terms of equal groups. Student AIS (Class PA5) offered a different explanation, saying 'Yes, because multipliers can also be used to find quotients, e.g., $10 \div 2=5$, as $5 \times 2=10$ '. This demonstrates some very strong understanding of the multiplicative situation and invites the question, "how did this student come to understand this point?' Whatever the case, it is certainly indicative of the capacity to think multiplicatively. A further five students tried to explain the reason as division being the 'inverse operation' or that 'division is pretty much the opposite of multiplication'. Whilst division is indeed the inverse of multiplication, neither explanation demonstrates an understanding of why the relationship works, in terms of factors and/or equal groups.

\section{Teacher Responses}

It can be seen from the above results and associated discussion that most students in the sample $(n=545) \mathrm{knew}$ about some of the content and ideas that underpin a conceptual understanding of the multiplicative situation but that they overwhelmingly failed to connect their knowledge to other ideas. Now it is important to consider what level of understanding is displayed by some of the teachers whose students were part of the sample. Teachers at School (PH) were given work samples generated from the MTQ and asked to comment on them, and they were also interviewed about aspects of multiplicative thinking.

They were shown a sample using arrays and asked what the sample showed about the students' understanding of the mathematics involved and also what teaching strategies they would employ to help each student. The samples are shown in Figure 2.

Tommy and Jamie were asked to represent $3 \times 4$ with tiles. They responded in the following ways, respectively.
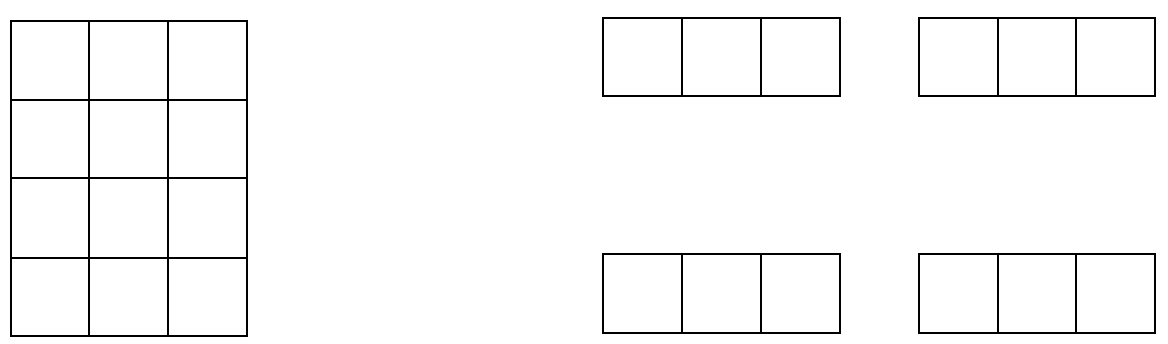

Figure 2. Work samples from Tommy and Jamie from teacher response sheet 


\section{Teacher $A$}

Teacher A responded with the following comment: 'Both have used arrays. Tommy perhaps sees the commutative aspect better. Jamie perhaps is comfortable with repeated addition'. No teaching strategy was suggested. When interviewed at a later date, Teacher A described how his students responded to a task based on the following combination problem: 'If I have seven shirts and three pairs of shorts, how many different combinations of shirts and shorts can I wear?' Teacher A was surprised when a number of his students drew an array to work it out, in preference to the method they had generally used before (i.e., a tree diagram). He had not suggested the use of the array. He was then asked specifically about arrays.

INT: How much do you use the array in your general teaching?

TEACHER A: If I'm honest with you, hardly ever ... hardly ever, and it's interesting that they all picked up on it [using the array]. Perhaps it's something I should be bringing into my practice.

Teacher A also said that as students move into the upper primary years, they are reluctant to use tools like the array and the number line and view them as things that are used in the early years.

There are several points worthy of note about the responses of Teacher A.

- He stated that both students in the sample used an array where they clearly did not. The second student depicted the number fact in terms of equal groups.

- Teacher A did not identify that in both cases the students' drawings showed $4 \times 3$ and not $3 \times 4$ as in the question.

- Even though he does not use the array and suggested that students are reluctant to do so, it was the array that was the preferred method of representation for the combination problem task he described.

- His comment that Tommy 'perhaps sees the commutative aspect better' is interesting and raises a couple of questions - Has Teacher A seen Tommy's array as being rotated from a 4 x 3 array? Does the fact that he does not use the array provide a reason why seven students in his class knew about the 'commutated law' or 'commutative law' but could not explain why it works in terms of an array?

\section{Teacher $B$}

Teacher B responded to the work samples shown in Figure 2 by saying 'Both have responded with logical answers, Tommy 3 by 4 and Jamie 4 lots of 3. Jamie may have some misconception'. It is of interest that Teacher $\mathrm{B}$ did not identify that Tommy used an array and her response about 'logical answers' is quite vague. Again, as with Teacher A, no suggestion about strategies has been made. Teacher B was also asked specifically about the use of the array.

INT: $\quad$ Do you use the array a lot?

TEACHER B: I think lower down the school they use arrays more but not after Key Stage One [approximately 7 years old]".

Teacher B also noted that the use of manipulatives falls away quickly once students move out of the early primary years.

\section{Teacher $C$}

Teacher $\mathrm{C}$ responded to the work samples shown in Figure 2 by saying 'Tommy and Jamie both understand that the multiplication requires either 3 lots of 4 or 4 lots of 3'. As a strategy, he suggested 'Work on representing calculations in different ways to deepen understanding'. Teacher $\mathrm{C}$ did not identify that Tommy had used an array and his explanation of the students' responses is unclear. Also, he did not identify that both students had depicted a $4 \times 3$ situation whereas the question was based on $3 \times 4$. Teacher C's response to the interview question about the array suggested that he may not have a clear idea of what an array actually is.

INT: $\quad$ In Year 6, do you use the array in your teaching?

TEACHER C: Is that the ... [pause] ...

INT: $\quad$ Rows and columns of dots.

TEACHER C: [further pause] ... No we don't, not in Year 6. No.

The collective responses from Teachers A, B, and C suggest that the array is not used in the upper primary classes in that school. This may serve to indicate why students in the school sample could not articulate why the commutative property works. It also provides a possible explanation, if this situation exists in general across the complete sample, as to why the depiction of the $4 \times 3$ number with an array declined with older students. That is, Table 3 shows that in the Year 4 (9 years) cohort, 62.9\% used an array, in the Year 5 (10 years) cohort, 60.8\% used an array, and in the Year 6 cohort, $44.5 \%$ did so.

\section{Teachers $D, E$, and $F$}

Further data were collected from interviews with three teachers at another school. These teachers were keen to follow up the use of the Multiplicative Thinking Quiz (MTQ) and were provided with a number of tasks which highlighted aspects of multiplicative thinking identified in the MTQ results. The responses of Teachers D, E, and 
F reflect some important learning in terms of their mathematical content knowledge and they also highlight how that knowledge was previously lacking. When asked about their level of awareness, Teacher D said,

"I'd never heard of things like the associative property [sic]. I understood that $5 \times 7$ is the same as $7 \times 5$ but I'd never heard those concepts. It's hard to explicitly teach kids that, if you're not naming them and understanding them".

Given the evidence about student understanding already presented, this is a particularly powerful comment and serves to underline a likely reason for students not being able to fully understand and connect mathematical ideas. Teacher E responded,

"With arrays, the bit for me that really helped was seeing an example of that strategy being used. . I'd never thought of teaching it that way nor did I understand the concepts beneath that".

Teacher F said,

"Once I started using arrays, I could see where that fits into what they should know, so now I do arrays, knowing that the length is one factor and the width is one factor . . . the kids have a strategy for understanding what factors actually are".

These responses are powerful and indicate two things - that the teachers' initial understanding was lacking and more importantly, that it is eminently possible to develop teacher knowledge when the teachers are receptive.

Teachers $\mathrm{D}, \mathrm{E}$, and $\mathrm{F}$ were also asked about how they would have reacted to student responses to questions such as those on the MTQ before they had become more aware of the underpinning mathematics. Teacher E said that they would 'randomly plugging holes' and Teacher D added,

"We wouldn't have been plugging those gaps in the past because we wouldn't have known that they existed ... if we'd asked them what an array was, they wouldn't have known but we wouldn't have recognised that as a gap".

Teacher F's comment about curriculum documents highlights another issue about teacher knowledge, that is, that teachers need to interpret curricula to successfully teach the content contained in it, but to do that, they need a rich understanding of the key concepts. Teacher F said,

"If you look at the curriculum documents, it's [multiplicative thinking] not stated explicitly anywhere, it's probably inferred that you would do it, but if you don't have any knowledge of it . . we had no knowledge of it originally, we weren't doing it and I don't think the curriculum is explicit enough".

Again, the comments from these teachers are powerful in that they highlight the impact of inadequate teacher knowledge on the practice of teachers. In particular, if teachers are unaware of what students do not know because they themselves do not know the content and understand the connections, the shortcomings in student knowledge will continue to go undetected. In addition, the curriculum (in this case the Australian Curriculum: Mathematics) may be seen by the teachers as lacking in advice for teachers about how to teach aspects of multiplicative thinking in a connected way.

The final word on teacher knowledge and practices comes from a teacher at another project school. She had observed students in her class doing the MTQ under the supervision of one of the research team and had noticed that many students had difficulty in answering the questions about factors. Following the administration of the MTQ, she remarked to the researcher, "I don't understand it. They struggled with the factor questions but I taught factors about three weeks ago". The significance of this comment relates to what Askew (2016) said about mathematical ideas being 'models for' rather than 'models of. He was talking about arrays but the same can be applied to factors which need to be seen not as a 'model of a number, but rather as a 'model for' understanding relationships between numbers, and then as 'tools for thinking with'. Like arrays, factors are not something to be 'taught' and then left but rather they need to be embedded in the daily discourse of the mathematics classroom so that students can see how they relate to, and can be used to explain other ideas. 


\section{CONCLUSIONS AND IMPLICATIONS}

The research questions posed were as follows:

- To what extent do children in Years 4, 5 and 6 (i.e., of ages 9, 10, and 11 years) think in a connected way to explain multiplicative concepts?

- What is the extent of teacher knowledge of multiplicative concepts?

It is apparent from the evidence presented that primary school students have the capacity to think multiplicatively and in a connected way but that capacity is often not fully developed. Most students have knowledge of aspects of multiplicative thinking as defined in the conceptual framework (Figure 1) but often do not connect that knowledge to enable them to understand multiplicative concepts. There is also evidence to suggest that teacher content knowledge may be unconnected and though the teacher data presented here is derived from a relatively small sample, there is clearly evidence of unconnected knowledge of multiplicative concepts in both students and teachers. It certainly seems to be an issue that warrants further research. Some conclusions worthy of consideration can be drawn from the presented data and they are listed here.

- The majority of students know about at least some aspects of multiplicative thinking.

- Students know about different aspects of the mathematics that underpins multiplicative thinking and not all students hold the same mathematical knowledge as do other students.

- A small minority of students in each of the three year/age levels were able to connect their knowledge of some of the mathematics and use it to explain other mathematical ideas in a conceptual way.

- Some students held a knowledge of all contributing mathematical ideas but did not connect their knowledge to understand multiplicative ideas in a conceptual way.

- The array is a central mathematical idea that underpins the multiplicative situation.

- Teacher content knowledge, specifically in relation to arrays, may be limited, at least within the places from where the sample for this study originated.

- Arrays are not widely used in middle and upper primary classes.

- Incomplete content knowledge of teachers is likely to mean that student misconceptions and misunderstandings may not be identified.

- Teaching of mathematical ideas like arrays, factors, and equal groups needs to be done in a sustained way where those ideas are more than 'models of mathematical ideas but rather 'tools for working with' and understanding those ideas.

Numerous people have lamented the lack of understanding that primary school students have about mathematical structure (Anthony and Walshaw, 2002; Warren and English, 2000). Feldman (2014) has indicated that a strong understanding of structure (such as factorisation) prepares students to deal with more complex ideas in flexible and efficient ways. Yet, the evidence presented here suggests that students hold 'pieces of knowledge' rather than the complete connected picture. The conceptual framework for this study is an attempt to represent some of the structure of multiplicative concepts. It is clear that many students hold knowledge of components of that structure but have not developed an understanding of how those components are connected, nor are they able to articulate such understanding through the use of essential mathematical language.

Thanheiser et al. (2013) suggest that the procedural view of mathematics held by teachers and PSTs is not helpful in preparing primary school students to understand mathematical structure. The findings here certainly do not suggest that teaching to develop connected understanding of concepts is prevalent in primary school classrooms. For example, out of a sample of 545 students, 511 (93.9\%) can identify the commutative property but most of them explain it in terms of a 'switch around' or a 'turn around', something that they have probably been taught and assimilated as a procedure. Similarly, 472 students (86.8\%) can identify the inverse relationship between multiplication and division but the vast majority explain it by saying that 'multiplication and division are from the same family' or something similar. Again, this displays a familiarity with the procedure but not necessarily the concept. As well, the words 'commutated' or 'commutative' were only used by 13 students from two classes, yet none of them said anything other than "It's the commutated law". They were not able to explain why it worked, suggesting that they were taught the name but not the understanding - a procedural approach. The importance of teachers holding a connected view of mathematical ideas was mentioned earlier in relation to Ma's (2010) knowledge packages. It is also evident in the 'connection' element of the Knowledge Quartet (Rowland, Huckstep and Thwaites, 2005) which enables teachers to structure lessons and sequences of lessons in a coherent way. Similarly, Ball, Thames and Bass (2008) conceptualised 'horizon content knowledge', part of which is teachers' ability to connect the specific mathematics at hand to other and larger mathematical structures and principles.

The conceptual framework presented in Figure 1 is the basis of this article, suggesting that the mathematical structure could be considered to contain those links and connections between the array, factorisation, factor pairs, and equal groups, and the two properties or relationships - commutativity and inverseness. It has been shown that 
most students know about some of the four underpinning ideas but have not connected them to articulating an understanding of the properties. Only four students out of 545 were able to make those connections. Does this mean that they did so as a result of explicit teaching or did the 'join up the dots' for themselves? The evidence presented here suggests the latter. The implications for teacher educators, education systems, and professional learning providers, are clear - unless PSTs and practising teachers have a rich understanding of mathematical structure in a conceptual rather than procedural way, they will not be equipped to make connections between mathematical ideas explicit for their students.

\section{REFERENCES}

Anthony, G. and Walshaw, M. (2002). Swaps and switches: Students' understandings of commutativity. In B. Barton, K. C. Irwin, M. Pfannkuch and M. O. J. Thomas (Eds.). Mathematics Education in the South Pacific (Proceedings of the 25th annual conference of the Mathematics Education Research Group of Australasia, Auckland, pp. 91-99). Sydney: MERGA.

Askew, M. (2016). Transforming primary mathematics: Understanding classroom tasks, tools and talk. Oxon: Routledge.

Askew, M., Brown, M., Rhodes, V., Wiliam, D. and Johnson, D. (1997). Effective teachers of numeracy: Report of a study carried out for the Teacher Training Agency. London: King's College, University of London.

Ball, D. L., Thames, M. and Bass, H. (2008). Content knowledge for teaching: What makes it special? Journal of Teacher Education, 59(5), 389-407. https:// doi.org/10.1177/0022487108324554

Baroody, A. J. (1999). The roles of estimation and the commutativity principle in the development of third graders' mental multiplication. Journal of experimental Psychology, 74, 157-193. https://doi.org/10.1006/jecp.1999.2524

Charles, R. I. (2005). Big ideas and understandings as the foundation for early and middle school mathematics. NCSM Journal of Educational Leadership, 8(1), 9-24.

Chick, H., Pham, T. and Baker, M. (2006) Probing teachers' pedagogical content knowledge: Lessons from the case of the subtraction algorithm. In P. Grootenboer, R. Zevenbergen and M. Chinnappan (Eds.), Identities, cultures, and learning spaces (Proceedings of the 29th annual conference of the Mathematics Education Research Group of Australasia, Canberra, pp. 139-146). Adelaide: MERGA.

Clarke, D. M., Clarke, D. J. and Sullivan, P. (2012). Important ideas in mathematics: What are they and where do you get them? Australian Primary Mathematics Classroom, 17(3), 13-18.

Davis, B. (2008). Is 1 a prime number? Developing teacher knowledge through concept study. Mathematics Teaching in the Middle School, 14(2), 86-91.

Downton, A. (2008). Links between children's understanding of multiplication and division and solution strategies for division. In M. Goos, R. Brown and K. Makar (Eds.), Navigating currents and charting directions (Proceedings of the 31st annual conference of the Mathematics Education Research Group of Australasia, pp. 171-178). Brisbane: MERGA.

Downton, A. (2013). Making connections between multiplication and division. In V. Steinle, L. Ball and C. Bardini, (Eds.), Mathematics education: Yesterday, today, and tomorrow (Proceedings of the 36th annual conference of the Mathematics Education Research Group of Australasia, pp. 242-249). Melbourne, VIC: MERGA.

Feldman, Z. (2014). Rethinking factors. Mathematics Teaching in the Middle School, 20(4), 231-236. https://doi.org/10.5951/mathteacmiddscho.20.4.0230

Gojak, L. M. (2013). It's elementary! Retbinking the role of the elementary classroom teacher. Available at: http://www.nctm.org/News-and-Calendar/Messages-from-the-President/Archive/Linda-M_-Gojak/It_s-

Elementary!-Rethinking-the-Role-of-the-Elementary-Classroom-Teacher/

Hurst, C. (2015). The multiplicative situation. Australian Primary Mathematics Classroom, 20(3), 10-16.

Jacob, L. and Mulligan, J. (2014). Using arrays to build multiplicative thinking in the early years. Australian Primary Mathematics Classroom, 19(1), 35-40.

Larsen, S. (2010). Struggling to disentangle the associative and commutative properties. For the Learning of Mathematics, 30, 37-42.

Ma, L. (2010). Knowing and teaching elementary mathematics: Teachers' understanding of fundamental mathematics in China and the United States. Mahwah, NJ: Erlbaum.

Matney, G. T. and Daugherty, B. N. (2013). Seeing spots and developing multiplicative sense making. Mathematics Teaching in the Middle School, 19(3), 148-155. https://doi.org/10.5951/mathteacmiddscho.19.3.0148

Mills, J. (2015). Professional knowledge required when teaching mathematics for numeracy in the multiplicative domain. In M. Marshman, V. Geiger and A. Bennison (Eds.), Mathematics education in the margins (Proceedings of the 38th annual conference of the Mathematics Education Research Group of Australasia), pp. 429-436. Sunshine Coast: MERGA. 
Rowland, T., Huckstep, P. and Thwaites, A. (2005). Elementary teachers' mathematics subject knowledge: The Knowledge Quartet and the case of Naomi. Journal of Mathematics Teacher Education, 8(3), $255-281$. https://doi.org/10.1007/s10857-005-0853-5

Siemon, D. (2013). Launching mathematical futures: The key role of multiplicative thinking. In S. Herbert, J. Tilley and T. Spencer (Eds.), Mathematics: Launching Futures (Proceedings of the 24th Biennial Conference of the Australian Association of Mathematics Teachers, pp. 36-52), Adelaide: AAMT.

Siemon, D., Breed, M., Dole, S., Izard, J. and Virgona, J. (2006). Scaffolding Numeracy in the Middle Years - Project Findings, Materials, and Resources, Final Report submitted to Victorian Department of Education and Training and the Tasmanian Department of Education. Available at: http://www.eduweb.vic.gov.au/edulibrary/public/teachlearn/student/snmy.ppt

Siemon, D., Bleckly, J. and Neal, D. (2012). Working with the Big Ideas in Number and the Australian Curriculum: Mathematics. In B. Atweh, M. Goos, R. Jorgensen and D. Siemon, (Eds.), Engaging the Australian National Curriculum: Mathematics - Perspectives from the Field. Online Publication: Mathematics Education Research Group of Australasia pp. 19-45.

Skemp, R. (1976). Relational understanding and instrumental understanding. Mathematics Teaching, 77, $20-26$.

Sullivan, P. (2008). Mathematical Discipline Knowledge Requirements for Prospective Primary Teachers, and the Structure and Teaching Approaches of Programs Designed to Develop That Knowledge. In P. Sullivan and T. Wood (Eds.) Knowledge and Beliefs in Mathematics Teaching and Teaching Development. Vol. 1, (pp. 1-9). Rotterdam: Sense Publishers.

Squire, S., Davies, C. and Bryant, P. (2004). Does the cue help? Children's understanding of multiplicative concepts in different problem contexts. British Journal of Educational Psychology, 74, 515-532. https://doi.org/10.1348/0007099042376364

Thanheiser, E., Philipp, R. A., Fasteen, J., Strand, K. and Mills, B. (2013). Preservice teacher interviews: A tool for motivating mathematics learning. Mathematics Teacher Educator, 1(2), $137-147$. https://doi.org/10.5951/mathteaceduc.1.2.0137

Warren, E. and English, L. (2000). Primary school children's knowledge of arithmetic structure. In J. Bana and A. Chapman (Eds.) Mathematics Education beyond 2000 (Proceedings of 23rd annual conference of the Mathematics Education Research Group of Australasia, Fremantle, pp. 624-631). Sydney: MERGA.

Young-Loveridge, J. (2005) Fostering multiplicative thinking using array-based materials. Australian Mathematics Teacher, 61(3), 34-40.

Young-Loveridge, J. and Mills, J. (2009). Teaching Multi-digit Multiplication using Array-based Materials. In R. Hunter, B. Bicknell and T. Burgess, (Eds.) Crossing divides: Proceedings of the 32nd annual conference of the Mathematics Education Research Group of Australasia (Vol. 2). Palmerston North, NZ: MERGA.

Zazkis, R. and Campbell, S. (1996). Divisibility and multiplicative structure of natural numbers: Pre-service teachers' understanding. Journal for Research in Mathematics Education, 27(5), $540-563$. https://doi.org/10.2307/749847 